\title{
Canarias en los conflictos navales de 1727 y $1739-1748$. Nuevas aportaciones
}

\author{
Antonio Béthencourt Massieu
}

En 1955 publicaba una monografía titulada Ataques ingleses a Fuerteventura. $1790^{\prime}$. La segunda edición vio la luz en 1992. La precedí de unas Reflexiones sobre la trascendencia que la guerra maritima de corso supuso para las Islas Canarias durante la modernidad ${ }^{2}$. En 1977 el profesor Alejandro Cioranescu había llamado la atención sobre cómo tema tan vital había sido desatendido por la historiografía regional ${ }^{3}$. En efecto, salvo Antonio Rumeu de Armas que con su voluminosa y magistral obra, Piraterías y ataques navales ${ }^{4}$, poco más es lo que sabemos sobre la guerra naval en este ámbito oceánico. Afortunadamente, no hace mucho acaba de ser reeditada con título más ajustado a su contenido: Canarias y el Atlántico. Piraterías y ataques navales ${ }^{5}$. Quizás sea la causa del alejamiento de los historiadores la ingente aportación del profesor Rumeu, de una parte, y de otra la enorme dispersión de las fuentes.

La relectura de esta obra me ha conducido imperativamente a profundizar en el análisis del fenómeno. Como resultado mi ponencia Reflexiones sobre la repercusión del corso maritimo en Canarias ${ }^{6}$ en un muy reciente Coloquio celebrado en Funchal (Madeira).

\section{EL PESO DE LA GUERRA DE CORSO}

En la ponencia llegué a una doble conclusión: Primera, la guerra del corso y los ataques navales al Archipiélago, consecuencia de su posición

Béthencourt Massieu, A., 1965.

Béthencourt Massieu, A., 1992 a y 1992 b.

Ciofanescu, A., 1977.

Rumeu de Armas, A., 1947-1950.

Rumeu de ARMas, 1991.

6 Béthencourt Massieu, A., 1994. 
estratégica, da origen más que a un «fenómeno de larga duración», a un "hecho estructural», que arrancando del siglo xV se prolonga hasta 1830. Segunda, persistencia que llevó aparejada la «fragilidad» del mismo durante las crisis bélicas; fragilidad, por otra parte, intrínseca a todos aquellos de su dimensión, como hace tiempo aseveró Ferdinand Braudel.

Para un estudio riguroso de los complejos efectos producidos por esta modalidad bélica sobre el pasado de las Islas - producto negativo, si se quiere, de su "renta de posición» geoestratégica- los vacíos y carencias son en la actualidad de tal envergadura que imposibilitan cualquier intento de aproximación a una valoración de orden cuantitativo ni siquiera al número de barcos apresados y mucho menos a una evaluación de las pérdidas materiales o humanas producidas por tan incómodos huéspedes. Reconozco que mi intento de aproximación con las 172 presas documentadas, elevables al menos a 198, para la larga centuria, es todavía cifra lejana a la totalidad de las capturadas.

Como subrayaba en Funchal, sólo mediante la aplicación de una metodología adecuada, consistente en crear un amplio equipo que permita realizar un rastreo sistemático de los archivos locales y nacionales, tanto españoles como extranjeros, y al tiempo recabar de nuestros colegas el suministro de los nuevos datos con que tropiezan en su quehacer archivístico, podríamos alcanzar el objetivo propuesto?. Mas si tenemos en cuenta que el corso y sus resultados encierra una enorme complejidad de secuelas que afectan desde la vida y mentalidad de la población insular a las relaciones internacionales, por citar los dos extremos de un variado abanico, comprenderemos la complejidad del problema.

\section{CANARIAS EN LA GUERRA CONTRA LA LIGA DE HANNOVER}

En la segunda de las líneas metodológicas apuntadas me ha parecido de cierta utilidad traer a cuento el papel que jugó Canarias durante la guerra sostenida por España en solitario contra la Liga de Hannover (1727) y de otra, aspectos inéditos sobre el tema durante la denominada Guerra de la Oreja de Jenkins (1739-1743), complicada más tarde con la promovida por la Sucesión de Austria ${ }^{8}$, que es como mejor la conoce la historiografía.

7 Béthencourt Massieu, A., 1994.

8 Béthencourt Massieu, A., 1954. La bibliografía sobre ambos conflictos es muy amplia y fue objeto con la política exterior de mi tesis doctoral. 
El enfrentamiento entre España y el eje Saint James-Versalles acabó con la declaración de guerra a la Liga de Hannover en 1727. Conflicto breve, al que se puso fin mediante la Preliminares de El Pardo de marzo de 1728. El conflicto se redujo al asedio de Gibraltar por un ejército español, mientras una escuadra al mando del vicealmirante Hossier no pasó de bloquear temporalmente Portobelo y La Habana, con la captura de algunas presas al tiempo que sufrían las tripulaciones los efectos sanitarios de las condiciones climáticas antillanas.

Por lo que toca a las aguas de Canarias, amén del frecuente paso de escuadras y navíos hacia América, durante este conflicto no se produjeron pérdidas de embarcaciones interinsulares 0 de pesqueros que faenaban en el banco Canario-sahariano. Explicación pausible: la vigencia, a pesar de la guerra, del comercio directo entre Canarias e Inglaterra, pervivencia de acuerdos subterráneos alcanzadas durante la guerra de Sucesión. Así se lo aclaran comerciantes ingleses residentes en el Puerto de la Cruz al famoso navegante Woodes Rogers de paso para América en $1708^{\circ}$. Habiendo cazado una embarcación, trató de forzar su rescate. Sus compatriotas mediante carta le comunicaron que abandonara su pretensión, porque supondría una descarada violación de lo que se ha estipulado en "secreto" ${ }^{10}$. Anomalía explicable, pues se trataba de una conveniencia mutua: las islas evitaban su aislamiento y desabastecimiento y los ingleses amén de malvasía obtenían algunas piastras americanas.

\section{Papel estratégico que juega Tenerife}

El por entonces comandante general de las islas don Lorenzo Fernández Villaviencio, marqués de Valhermoso, aunque fuera hombre despótico, aprovechado e impopular gobernante, era un buen estratega. Tanto que durante la crisis bélica, convirtió a la plaza de Santa Cruz de Tenerife no sólo en un centro neurálgico de información atlántica, sino nudo clave para las comunicaciones y coorćinación de las operaciones marítimas en el ámbito oceánico y antillano.

Así, recabó noticias desde diciembre de 1726 del armamento de dos flotas británicas que se armaban con destino al Báltico y al Caribe ${ }^{11}$.

\footnotetext{
9 Rumeu de Armas, A., 1991, tm. III, 235-239 y Santiago, M., 1944, 156-172.

10 Rumeu de Armas, A., 1991, tm. II, 244-270; Cioranescu, A., 1977, 114-115 y Béthencourt MAssieu, A, 1992 a.

11 El marqués de Valhermoso a marqués de Castelar. Santa Cruz de Tenerife (S. C. T.), $9.12 .727 ; 9$ y $23.2 .727 ; 18.3 ; 24.5 .727$, etc. Todas y cada una de las autoridades insulares le
} 
Comunicaba con prontitud esta noticia y la de cuantas embarcaciones armadas cruzaban entre las islas al secretario de guerra, Baltasar Patiño, marqués de Castelar y hermano del famoso político, al tiempo que colocaba al archipiélago en estado de defensa ${ }^{12}$.

En Santa Cruz se recibían con frecuencia noticias constantes del gobernador de La Habana, Martínez de la Vega, coordinador de las operaciones en el mar de las Antillas y Seno Mejicano, así como de don Luis Agustín del Castillo, cónsul de España en Funchal, observatorio de primer orden, pues era la base de apoyo de toda embarcación del Reino Unido en ruta al Nuevo Mundo.

\section{El eje Cádiz-Santa Cruz-La Habana}

De tal manera, que a través de la correspondencia entre Martínez de la Vega y Valhermoso podríamos seguir los movimientos de la flota del vicealmirante Hossier y sus peripecias: bloqueo de Portobelo, método utilizado para el suministro de sus barcos, refuerzos hasta alcanzar las 24 naves, así como los merodeos frente a La Habana y reconocimiento de las ensenadas a propósito para intentar un desembarco ${ }^{13}$.

La alarma se disparó cuando el cónsul de Funchal el 4 de mayo despachó una embarcación portuguesa sin carga que arribó a Santa Cruz de La Palma. Por ella comunicaba Castillo el trasiego de navíos para reforzar la escuadra de Hossier con el objetivo de establecer una cabeza de puente en la costa meridional de Cuba, bien en La Chorrera o en Bahía Honda.

Como no contara con embarcación, Valhermoso habilitó en tres días la balandra al servicio de la Renta del Tabaco en Tenerife, al mando de Marcial Garcés, "sujeto de toda experiencia e inteligencia», que realizó la travesía en el tiempo previsto, en algo menos de un mes ${ }^{14}$.

informaban con estricta prontitud. Archivo General de Simancas (AGS). Guerra Moderna, leg. 1747 .

12 El marqués de Valhermoso a marqués de Castelar. Santa Cruz de Tenerife (S. C. T.), 3.6.747. Loc. cit.

13 Anécdotas sobre como el suministro de tabaco para Hossier, fue utilizado para reconocer el potencial del enemigo. El naufragio de «El Rubím y la balandra "La Holandesa» con la odisea de las tripulaciones acogidas a un paquebote inglés, apresado poco antes cargado con víveres para reabastecer a Hossier. Encallaron en una baja cerca de la isla de Pinos. Martínez Vega a Valhermoso, La Habana, 18.4.727. AGS Guerra Moderna, leg. 1747

${ }_{14}$ Castillo a Vaihermoso. Funchal, 4.5 y 20.7.727. Valhermoso a Castelar, SCT, 18.7.727. Loc. cit. Es curioso hacer constar cómo Valhermoso enviaba una copia de sus pliegos a los contadores de la Renta de Tabaco de Barlovento y otros puertos, para asegurarse en caso de accidente de la embarcación de que el gobernador de La Habana los recibiría. O la pericia 
El peligro de un desembarco se evanesció rápidamente, pues la nueva campaña de Hossier ante Portobelo «que quebrantó con exceso a las tripulaciones", razón por la cual las unidades de su mando se redujeron a patrullar en pequeñas agrupaciones frente a las costas cubanas, y especialmente a vigilar La Habana ${ }^{15}$. Martínez de la Vega despacha a Valhermoso para que haga llegar los pliegos a la Corte y parece respirar por haber quedado reducidas a sólo 15 unidades la escuadra de Hossier. Vicealmirante que moriría poco después.

Valhermoso aprovecha para comunicar a Castelar que por un barco inglés del comercio del Puerto de la Cruz supo que los aliados de la Liga de Hannover esperaban muy contrariados, a causa de la permanencia en el istmo de las tropas que sitiaban Gibraltar, el consiguiente retraso de la paz. Sobre todo si Hossier capturara algunas unidades de los galeones españoles y fueran declarados como buena presa.

Al tiempo Valhermoso esta vez confía a sus superiores que el comercio directo continúa entre Canarias e Inglaterra, pero disimuladamente; porque los que vienen por vino enarbolan «bandera amiga, que como preciso para manutención por los comestibles y ropa que hacen para las islas, lo he admitido y continuaré», de lo que Felipe $V$ se dio por enterado el 15 de diciembre ${ }^{16}$

A las novedades remitidas por Castillo desde Funchal ${ }^{17}$, Valhermoso suma las por él recogidas, despachándolas con prontitud al intendente de Marina en Cádiz ${ }^{18}$. Novedades muy del agrado del soberano que «no deja de estimar el cuidado de V. E. en adquirir aviso". A esta fineza agrega Baltasar Patiño ya en marzo que se esperaba la paz por momentos, pues se habían retirado el grueso de las tropas que asediaban a Gibraltar, quedando sólo las indispensables para asegurar el bloqueo «en interim se allanan las mínimas diferencias» ${ }^{19}$.

náutica del marqués de Valhermoso que calculó con exactitud el tiempo de la travesia de la balandra o la orden de que se vendiera en La Habana, por considerar que la misma no reunía las condiciones de seguridad que le permitieran el retorno, dada la diferencia entre el viaje de ida y vuelta.

15 Martínez de la Vega a Valhermoso, 6.7.727. Loc. cit. Despacho que llegó a Santa Cruz a bordo del navio "Santísima Trinidad y San Marcos", cargado de tabaco de la Real Hacienda, pues otra que había salido con anterioridad fue capturada por el enemigo. Eran del tráfico con las Islas. Da cuenta de la retirada del enemigo.

${ }_{16}$ Valhermoso a Castelar, SCT, 13.10.727. Leg. cit.

17 Funchal, 7.1.728. Leg. cit.

18 Castelar a Valhermoso. El Pardo, 16.3.728. Minuta. Leg. cit.

19 LOC. cit. 
A modo de conclusiones

Restaurada la paz, que afortunadamente esta vez para las islas duró una docena de meses, como balance de este breve conflicto merecen ser subrayados dos aspectos:

Durante la crisis bélica, por lo que toca a las Canarias excepcionalmente no sufrieron durante la misma las duras pérdidas que suponía la guerra de corso, gracias a mantenerse el denominado «comercio directo». A las necesidades perentorias de los isleños, puede que se sumen los beneficios del comandante general como juez protector que era de los mercaderes británicos.

De otra parte, el papel de centro neurálgico jugado por Santa Cruz de Tenerife por lo que atañe a recogida de informaciones y nudo de comunicaciones. Hecho que supuso el abandono momentáneo de un retorno más seguro y rápido por Azores en tiempos de paz, pero que fue sustituido en busca de seguridad por el eje Cádiz-Santa Cruz-Habana. Novedad más significativa por no haberse utilizado ni antes ni después de este conflicto. Sin embargo, resultó eficaz gracias a la experiencia acumulada por los capitanes de los registros del comercio canario con América.

\section{LA GUERRA DE LA OREJA, 1739-1748}

Este conflicto fue muy diferente del anterior. Por lo que toca su larga duración, como por los efectos catastróficos que la guerra de corso supuso para las Islas Canarias. La razón de semejante actitud fue la imposición de la guerra por parte de la oposición whig, armadores y comerciantes, quienes esperaban enormes beneficios, dada la superioridad naval de Inglaterra, frente al sistema de paz diseñado desde años antes por Walpole, Fleury y Patiño ${ }^{20}$.

El balance de esta guerra no pudo ser peor. Al menos fueron 46 las embarcaciones perdidas que he logrado documentar. Número solamente superado por las 61 que cayeron durante la guerra contra Inglaterra de 1805 a 1808. Las 46 de la guerra de la Oreja representaron el $26,75 \%$ de las que sucumbieron entre 1701 y $1830^{21}$.

20 VAuChef, P., 1924. Es la tesis central del libro.

21 Béthencourt Massieu, A., 1994. Cuadro XIX. 
Los sucesos bélicos en aguas del Archipiélgo han sido objeto de estudios por historiadores insulares. Alguno exhaustivamente ${ }^{22}$. En razón de lo anterior ahora me reduciré a unos cuantos aspectos y hechos, unos inéditos y otros porque estimo introducir alguna matización. Me referiré al desembarco de ingleses en El Juncal (Gran Canaria), el realizado en Veneguera (Gran Canaria), ambos en 1745, así como los ataques a La Gomera y Los Cristianos (Tenerife) en 1746. Pero antes haré alguna referencia al canje y trato de prisioneros y al comercio directo Canarias e Inglaterra, a pesar de las operaciones bélicas en corso.

\section{El canje de prisioneros de 1743}

Aunque esta operación ha sido descrita suscintamente por Rumeu de Armas, documentación de Simancas permite intentar introducir un análisis y mayor precisión ${ }^{23}$.

El comandante Robert Erskine recibió instrucciones del Almirantazgo para que al mando de la fragata de la Navy transportara para ser canjeados en Santa Cruz de Tenerife los prisioneros canarios concentrados en Plymouth. Recibieron éstos dos terceras partes de la ración de la marinería, siendo vigilados por 30 soldados.

La fragata se mantenía frente a Santa Cruz, por lo que el comandante general envió en misión informativa al cónsul de Holanda, Arnaldo Wanstheinfort. Pero mientras hacía la visita, desembarcaba con bandera de parlamentario el teniente de fragata Francisco Castellano ${ }^{24}$. Propuso al general Benito el canje de 24 canarios y 41 españoles capturados a bordo de una balandra corsaria en ruta Plymouth-Santa Cruz. Previo informe del subdelegado del Almirantazgo español en Canarias, Domingo Miguel de la Guerra, se procedió al intercambio, pues eran unos 80 los ingleses prisioneros, aunque diez renunciaron a embarcar por «haberse reducido a nuestra Santa Fe Catholica». A la vista del buen trato recibido por los

22 Rumeu de Armas, A., 1991, tm. III, 247-48 y Béthencourt Massieu, A., 1954 para los ataques a Fuerteventura. Rumeu de Armas A., 1991, tm. Ill, 242-248; Darias Padrón, D. V., 1936, 124-130 y SANTIAGO, M., 1943 para los ataques a La Gomera y correrías de Charles Windham.

23 Rumeu, 1991, tm. III, 369. Bonito a Campillo. SCT, 17.2.723. Erskine a Bonito, a bordo del «Fox», 5.2.743. (estilo antiguo). Ensenada a Bonito. San Ildefonso, 27.8.743. AGS, Guerra Moderna, leg. 1289. Los primeros prisioneros ingleses encerrados en el Castillo de Paso Alto en Santa Cruz fueron 15. Nueve procedentes de una presa realizada por el corsario Jacques Canese y el resto por Antonio Miguel con su San Telmo.

24 El tal Castellano era un canario, capturado a la altura de Jamaica en 1741, cuando regresaba de Caracas al mando de un registro de La Palma. 
canarios y a la gentileza de Erskine, el comandante general le autorizó para que realizaran aguada.

El profesor Rumeu nos relata cómo unos días más tarde arribó un navío al mando de Charles Holmes. Solicitó canjear prisioneros y ofreció rescatar un bergantín canario que había capturado. Propuesta que realizó por medio de un lego franciscano y el patrón del bergantín. Como no había prisioneros y Bonito hubiera prometido a Erskine liberar a los ingleses aprisionados en el futuro, Holmes liberó a los 24 canarios en su poder, rescatando el bergantín su dueño, con lo que abandonó aguas canarias $^{25}$.

\section{Comercio directo con Inglaterra}

Interesa destacar cómo durante una guerra tan enconada no se perdió en Canarias del todo la tradición de sostener el tráfico directo con Inglaterra.

Robert Eskine traía junto con el canje de prisioneros otra misión: restaurar el tráfico directo a la vista de la miseria reinante en las Islas Canarias por no tener salida sus vinos de una parte, y de otra la posibilidad de que los mercaderes británicos obtuvieran remuneradores beneficios. Erskine tenía "entendido que en las últimas guerras no hubo interrupción en el comercio de la Gran Bretaña con estas Islas ${ }^{26}$.

Como quiera que ambos interlocutores carecian de poderes, se acordó que ol inglés expusiera ante el Almirantazgo, mientras Bonito recabaría de Campillo la correspondiente autorización. Caso de alcanzarse el acuerdo, se suprimiría el corso en aguas de Canarias. El cónsul holandés Wanstheinfort se encargaría del intercambio de la correspondencia.

Tanto el comandante general como el subdelegado del Almirantazgo en las Islas apoyaron con énfasis la propuesta ante la Corte ${ }^{27}$. Es más,

25 Rumeu de Armas, A., 1991, tm. III, 369. Según este autor el nombre del navio era "The Shapphir" y el bergantín nada menos que el corsario "San Telmo" de Antonio Miguel. Además traía apresada otra embarcación canaria, "El Rosario". El comandante general consiguió incluso que Holmes liberara al capitán de un corsario vizcaíno, apellidado Bernis. Bonito a Ensenada, SCT, 14.7.743. Leg. cit.

26 Cfr. Nota 23, carta cit. de Erskine a Bonito.

27 Bonito recuerda a Campillo que al abrir la correspondencia del cónsul Crosse, encontró una propuesta semejante, como único remedio "de aliviar la miseria que padecian estos naturales". Añadiendo que necesita una propuesta concreta, pues la ofrecida por Ustáriz como paliativo era insuficiente, ya que se reducia a que «con prudente disimulo tolerase la introducción de viveres», ya que en este caso la entrada no quedaría compensada con la «extracción 
Bonito opina que no cree que el privilegio solicitado sea excesivo, pues sabe por prisioneros que han deambulado por Londres que «allá se admiten las lanas de España, a donde se extraen con permiso de $S . M$.».

En cuanto a la dificultad de neutralizar las aguas del Archipiélago, no ofrece la menor dificultad a la luz de lo previsto en el capítulo XXXII de la Ordenanza de 17 de noviembre de 1718, regulando la guerra de corso $^{28}$.

A petición del marqués de la Ensenada, por fallecimiento de Campillo, alguien que ignoro redacta un informe, en el que se aprueba el libre comercio con Inglaterra en razón de que la única fuente de ingresos de los canarios es la salida del vino "que se halla enteramente aniquilado" con el consiguiente descenso en la percepción de derechos de aduana. $Y$ como los canarios continúan suministrándose mediante el contrabando con la consiguiente salida de la moneda de buena ley, y la fidelidad de estos vasallos a Felipe $V$, el rey consentirá para evitar la hemorragia monetaria hacia Madeira, que se admita el comercio de géneros británicos, pero no directo, sino mediante embarcaciones que cubran la mercancía «bajo bandera amiga», pagándose como en la guerra pasada el 15 por 100 de habilitación, además de los regulares derechos de aduana ${ }^{29}$.

De esta forma, más que una solución, la decisión resultó un mero paliativo, pues no se lograba un objetivo imperioso: la neutralización de las aguas de Canarias con lo que se mantenía la desastrosa guerra de corso. Si bien se falicitaba la salida de parte de la cosecha de vino, no acababa de poner freno a la salida de la plata. La Hacienda Real se veía beneficiada con el 15 por 100 de habilitación y continuaba presente el telón marítimo, incluso con el tráfico interinsular, imprescindible para el temprano mercado regional, basado en la complementaridad de la producción de las Islas y el reducido coste del transporte marítimo ${ }^{30}$.

de la malvasía», teniendo que cubrir la diferencia con morieda. Bonito a Ensenada, 17.2.743. ya cit.

${ }^{28} \lll$... en la que se prescriben las reglas con que se debe hacer el corso, prohibiéndose a los corsistas en dicho capitulo el poder pasar a Indias, ni a las Islas Canarias, ni Madera sin permiso de S. M." LOC. cit.

${ }_{29}$ «Habiéndose puesto en conocimiento del Rey que por la isla de Madera se introduce fraudulentamente en Canarias muchos géneros de Inglaterra, extraiéndose moneda», y al tiempo la necesidad de aumentar la percepción de derechos en las aduanas de las Islas, al tiempo que se favorece la salida del malvasía. Ensenada a Bonito. San Ildefonso, 27.8.743. Leg. cit. Orden semejante fue despachada al administrador general de Aduanas, Juan Frachy.

30 Como ejemplo de esta realidad véase la carta de Bonito a Campillo. SCT, 28.4.743. AGS, Guerra Moderna, leg. 1239. 
Dos desembarcos y dos ataques

Después del asalto de Windham a La Gomera por agosto de 1743, las aguas del Archipiélago gozaron, a pesar de continuar la presencia de algún corsario, de dos años de extraña tranquilidad. La única explicación radica en las negociaciones entabladas en pro del restablecimiento del comercio directo. Como el resultado fuera tan ambiguo, en 1745 e inicios del siguiente volvieron las zozobras, alertas, pérdidas de embarcaciones, desembarcos y ataques. Sin embargo, ni fueron muchas las naves perdidas, ni tampoco de gran trascendencia los ataques.

La posibilidad de dar a conocer alguna y añadir nuevas precisiones a otras de estas acciones, es lo que me anima a escribir las siguientes páginas.

\section{El ataque contra el Juncal (Gran Canaria)}

El 9 de febrero de 1745 surgió entre las islas una escuadrilla integrada por cinco naves corsarias. Dos de ellas bloquearon el puerto de Santa Cruz de La Palma, mientras el resto se situaban ante Santa Cruz de Tenerife. Sorprendieron dos balandras del tráfico interinsular cargadas de trigo. Luego cambiaron de táctica. Mientras los corsarios bloqueaban la entrada a Santa Cruz de Tenerife, cinco lanchones, armados con pedreros y los barcos capturados convenientemente artillados, enarbolando bandera francesa, cruzaban las doce leguas que separan la punta de Anaga, extremo septentrional de la isla de Tenerife y el extremo noroccidental de la de Gran Canaria. La estratagema dio resultado, pues cayeron en sus redes dos fragatas francesa de la Compañía Real de Guinea, que procedentes de Port Louis, se vieron obligadas a causa de los destrozos de un fuerte temporal a reparar en Canarias. Poco más tarde era un bergantín canario con pescado salado, la víctima. El comandante general pudo despachar de noche barquitos a todas las islas, con lo que acabaron las presas.

A los corsarios acabó de presentárseles el problema habitual: necesidad de agua y víveres. Mientras dos corbetas se mantenían frente a Santa Cruz de Tenerife, el navío con las otras dos corbetas, cinco lanchones y los barcos capturados se arrimaron a Gran Canaria y eligieron como lugar idóneo para el desembarco el puerto de El Juncal, situado al Norte del de Las Nieves y al sur del de Sardina. En el puerto de El Juncal desemboca el barranco de este nombre que separa en la actualidad los municipios de Agaete y Gáldar. 
La operación planeada tenía sus riesgos pues estaba alertado el Regimiento de Guía del mando de don José de Andonaegui. Tan pronto comenzaron los preparativos del desembarco, acudió a defender la playa la compañía de don Agustín del Castillo y poco más tarde el resto del Regimiento de Guía. El desembarco se reducía al avance hacia la playa de lanchones con pedreros y barcos capturados, auxiliados por la artillería durante siete horas, sin ceder un paso los defensores, lo que les obliga a la retirada de los atacantes ${ }^{31}$. Este ataque ha sido localizado hasta ahora de forma inconcreta en el puerto de Las Nieves, salida del pueblo de Agaete $^{32}$.

\section{Desembarco en Gran Rey (La Gomera)}

Pasaban los días y con ello aumentaba la sed. El 18, después de nueve días de merodeo, eligieron como escenario La Gomera y más específicamente su capital, San Sebastián. El comandante de las armas, don Diego Bueno, el heroico defensor contra Windham ${ }^{33}$, disparó un cañonazo sin bala para que la escuadrilla se identificase. Al entender éstos que era plaza artillada, desistieron. Pero la necesidad de agua era tal, que «se fueron a otro cabo opuesto de la Isla», es de suponer que en las inmediaciones del Valle de Gran Rey, «y por ser despoblado desembarcaron ochenta hombres». Observado por una mujer desde un altonazo "dio voces a unos pastores y estos segir [sic] su gritería, con amago de buscarlos, volvieron a embarcar precipitadamente, sin otro efecto ${ }^{34}$. Sin embargo, hay que suponer que lograron cargar algunas pipas con agua. Don Diego Bueno al dar parte de estos sucesos lamenta que «los ingleses hayan puesto pie en su |s|a, La Gomera» ${ }^{35}$, debido a la distancia y lo abrupto del camino.

31 Llegó el Regimiento de Guía «aquella marina a impedir el desembarco, lo que ejecutaron con tanta bizarría que sufrieron a cuerpo descubierto siete horas de continuo fuego de la artillería del navío y pedreros y fusilería de los cuatro lanchones; y los paisanos recogieron alguna porción de balas de artillería, que les enviaron al referido Comandante", Andoanegui. Mesones de Lima a Ensenada. SCT, 23.3.745. AGS. Guerra Moderna, leg. 1306

32 Rumeu, A., 1991, tm. III, 269.

33 Loc. cit.

34 Carta citada de Mesones de Lima

35 Lamenta Bueno la distancia y lo abrupto de los caminos, lo que según él permitió a los ingleses "ser los primeros que podían contar con haber pisado terreno de aquella isla sin verter sangre». "Cuya expresión - comenta Masones a Ensenada-- nacida de su natural celo, me ha parecido no escusarla de la noticia de V. E., por lo que se hace acreedor de la Real Piedad de S. M., lo que executó el año pasado 43 en defensa de aquella Isla». Carta cit. Inglés puede que no, pero en 1571 el rochelés Jean de Capdeville no sólo tomó San Sebastián, sino que ia saqueó e incendió, con tripulación franco-inglesa. Rumeu, 1991, tm. I, 547-556. 
La campaña que les sonrió en los inicios a los corsarios, logrando en poco tiempo capturar cinco presas, comenzó a convertirse en odisea, al padecer sed y no encontrar embarcaciones que apresar por la rigurosa interrupción del tráfico interinsular. La resistencia de los milicianos en los intentos de poner pie en tierra, les obligó a una retirada. Hecho que provoca el elogio del comandante general Masones de Lima hacia las Milicias $^{36}$, clave explicativa del fracaso de la casi totalidad de los intentos de desembarco a lo largo de tres siglos.

\section{El desembarco en Veneguera (Gran Canaria)}

Por octubre de 1745 zarpaban de Liverpool una fragata de 30 cañones y una corbeta armadas en corso. Como no tuvieron suerte en el Golfo de Vizcaya, decidieron alargarse a las Canarias "a esperar los navíos de Indias».

Fueron localizadas por los vigías de Tenerife el 11 de diciembre, el mismo día en que capturaban a la salida del Puerto de la Cruz — «que salió de La Orotava»- una goleta portuguesa. El capitán de ésta, el práctico y un fraile agustino, que embarcó como pasajero, quedaron a bordo como rehenes. El comandante general don Luis Mayoni hizo circular entre las islas orden de cerrar los puertos "evitando así que cogieran algunos de nuestro barcos" para que a la vista del poco negocio «fuese corta su subsistencia en estos mares" ${ }^{37}$.

Destacaron la goleta ante el puerto de Santa Cruz de Tenerife, "creo que a reconocerlon, en opinión de Mayoni. Como en el mismo ultimaran sus preparativos dos navíos de registro del comercio de Canarias con América y pudiera llegar la noticia a los corsarios, el comandante general preparó algunas lanchas armadas que obligaron a la goleta a situarse bajo el fuego de la artillería de la plaza, donde fue detenida y asegurada ${ }^{38}$.

Los barcos corsarios merodearon en las cercanías de Gran Canaria y el 21 volvieron sobre Santa Cruz para reconocer el puerto. El 26 se dejaron ver por la costa del Poniente de Gran Canaria.

\footnotetext{
${ }^{36}$ "... no puedo dexar de ponderar a V. E. la puntualidad, amor y celo con que voluntariamente, y casi sin necesitar órdenes de sus superiores se muevan los naturales a la defensa de sus islas. Es de compadecer la falta de municiones correspondientes al resguardo de ellas". LoC. cit.

${ }^{37}$ Mayoni a Ensenada. SCT, 2.1746. AGS, Guerra Moderna, leg. 1307

38 Loc. cit.
} 
La falta de agua les obligó a elegir un lugar despoblado: Veneguera, situado al sur de la Aldea de San Nicolás de Tolentino, seguramente siguiendo las indicaciones del práctico. Desembarcaron 24 hombres y «tres cañoncillos de campaña» que les permitiera cubrir la retirada en caso de necesidad.

Un pastor dio aviso a La Aldea. La compañía de milicianos de este lugar con algunos de la jurisdicción de Tejada acudieron con gran celeridad. Los corsistas fueron sorprendidos cuando se dedicaban al pillaje de ganado, con lo que estaban dispersos. Atacados «con la intrepidez que acostumbran estas milicias», corrieron a «tomar con precipitación sus lanchas» ${ }^{39}$. Los invasores dejaron en su huida un muerto, un herido y cuatro prisioneros todos irlandeses. Aprovechando la confusión se entregaron a los milicianos un tripulante, el capitán de la goleta, y el práctico que los guiaba. Abandonaron algunos fusiles, sables y pistolas, despojos que con consentimiento del comandante general fueron ofrecidos por los combatientes a "María Santísima de Guía, que es su protectora". Ofrenda significativa de cómo a mediados de la centuria de la tolerancia, todavía supervivía de alguna manera el espíritu de las guerras de religión. La sorpresa de estos confiados británicos motivó el regreso a su base 10gística, Funchal, el último día del año 1745.

Finalmente, es necesario destacar, cómo al fracasar como arma defensiva el contracorso, como he tenido ocasión de afirmar en otro lugar ${ }^{40}$, el único sistema que garantizaba la defensa contra los corsistas enemigos, aunque fuera duro para los canarios, consistió en cerrar herméticamente los puertos para obligar a los huéspedes a prolongara sus cruceros, prolongación consecuencia de la poca rentabilidad del armamento, lo que indefectiblemente les conducía a tratar de desembarcar en demanda de agua y viveres frescos. Aquí caían severamente castigados por unas milicias rápidas en acudir y de enorme eficacia en la pelea. Consecuencia, la retirada de las aguas de la latitud de las Canarias.

\section{Ataques a la Gomera y Los Cristianos (Tenerife)}

No se había evanescido esta alarma, cuando entre el 3 y 4 de enero se supo la presencia «a los extremos de Tenerife por la banda Norte», de dos fragatas de la Royal Navy de 50 y 24 cañones respectivamente. Según

39 LoC. cit.

40 BÉTHENCOURT, A., 1994. 
informe de Funchal habian recibido el cometido de interceptar el tráfico entre islas, debiendo ser sustituidas por un relevo al final de la campaña ${ }^{4 i}$.

Mayoni esta vez con mayor tranquilidad y perspicacia que sus predecesores hizo funcionar su sistema de alarma y cierre hermético de los puertos. Así evitaba sorpresas y «la subsistencia en estos mares de los corsarios, que es seguro les daría fomento si apresaran algunas de nuestras embarcaciones». La táctica aparejó un resultado óptimo, pues como se afirma en la Relación ${ }^{42}$, y no sin ironía, "parece que cansados de pasearse inmediatos estas costas, sin más frutos que el que puede ofrecerles la vista de estos riscos y adelantar la práctica de la navegación», se decidan a pasar a una acción más contundente, y de resultado previsible.

En efecto, el día 16 se aproximaron al puerto principal de La Gomera, «bien aterrados y en disposición de saltar». Trataban de apoderarse de dos barcos fondeados en el mismo y sacarlos después de tomarlos al abordaje desde cinco lanchas «bien tripuladas y armadas en guerra» y protegidas por la artillería de las fragatas. "De cuya empresa desistieron al principio de intentarlo, al mismo tiempo que la artillería de aquellos pequeños castillos los tuvo en proporción de poderles disparar; lo que no fue $\tan \sin$ acierto que no reconociese haberles hecho algún no corto daño» ${ }^{43}$.

Al siguiente día volvieron al mismo paraje las dos fragatas, mientras cruzaba más a lo largo otra embarcación de mayor porte «que hasta hoy se tiene de por línea". Bordearon la costa y las inmediaciones de la ciudad, pero de sus movimientos no pudieron los gomeros conjeturar las intenciones.

El 18 a la una de la tarde surgían las dos fragatas ante el puerto de Los Cristianos, en la banda sur de Tenerife. Pensaron que sería fácil presa la de un barco canario con carga de trigo allí refugiado, pues toda la defensa se reducía a una simple trinchera en la playa. Dieron fondo en el puerto que tiene bastante calado como a las cinco de la tarde, «en el mismo sitio donde lo acostumbran nuestros barcos», lugar abandonado

41 Mayoni a Ensenada, SCT, 24.1.746. AGS, Guerra Moderna, leg. 1309. La información sobre clase, parte, armamento y objetivos, se recibieron del cónsul de España en Funchal.

42 Relación de lo sucedido en el principal Puerto de la Isla de La Gomera y de los Christianos, situado en la banda sur de Thenerife, contra dos fragatas inglesas que intentaron sacar dellos unos barcos en los días 16,17, 18 y 19 de henero deste presente año de 1746. AGS, leg. cit

3 LoC. Cit. 
por la embarcación canaria, que en busca de seguridad fue varada en la playa.

Las fragatas abrieron fuego contra el barco y la trinchera, ocupada ya por hombres del Regimiento de Abona al mando del capitán comandante don Juan Rodríguez Feo. Inmediatamente largaron cinco lanchones con el fin de sacar el barco varado con el apoyo de la artillería. Cuando los lanchones estuvieron a tiro recibieron una descarga cerrada, seguida de fuego a discrección, realizados con «tanto acierto y vigor que los obligaron a retirarse, no obstante la superior fuerza que las acompañaba» ${ }^{44}$.

Continuó el bombardeo mientras los lanchones se reagrupaban. Volvieron al intento. El fuego vivo se mantuvo por una hora hasta que cedieron los botes atacantes «al acierto de nuestros tiros y valor de la milicia, retirándose a sus navíos con bastantes pérdidas, según pudo observarse».

La noche no supuso tregua. Desde las fragatas observaron cómo acudían a la marina el resto de los milicianos del Regimiento. Sobre ellos disparaban balas y palanquetas, inmovilizándoles, hasta que el comandante ordenó apagaran las teas, cubriéndose tras un barranco, «desde donde podían desfilar fácilmente a las trincheras».

Para la defensa fue factor inapreciable la proximidad de la Casafuerte de Adeje, situada a una legua de camino. Su castellana, doña Florencia Pizarro Picolomini de Aragón, condesa de La Gomera y marquesa de Adeje ${ }^{45}$, sacó de su fortaleza 20 pedreros, diez barriles de pólvora y otro armamento «asegurándose por este medio el triunfo al Rey y gloria a la Patria” ${ }^{46}$.

Al amanecer del día 18 se encontraban situados en la trinchera más de ochenta hombres. Se aproximaron las lanchas armadas y fueron nuevamente rechazadas «con más violencia y tal pérdida (según se conjetura) que no volvieron a acercarse a nuestro fuego, contentándose con formar en línea delante de sus navíos y acompañar el disparo de sus pedreros».

Es entonces cuando surge lo insólito, pero prefiero ceder la palabra a la Relación. El texto es testimonio inapreciable para el estudio de las mentalidades y comportamiento colectivo:

44 LOC. cit.

45 Viera Y Clavijo, J., 1982, tm. II, 79

46 Entrega a los milicianos además de fusiles, picas, espadas anchas, diez barriles de pólvora con la munición correspondiente. Todo este material fue trasladado a lomos de 12 camellos. Además de alimentos para un regular sustento de los miliciamos. Loc. cit. 
«Viendo nuestra gente su retirada y no pudiendo ya sujetar su orgulloso deseo de castigar a los enemigos, sin que fuera bastante a contenerlos las órdenes que tenían dadas el expresado Comandante, dejaron la retirada y trinchera y se pusieron a campo descubierto en la playa; en donde, vitoreando al Rey nuestro Señor y tirando los sombreros al aire, llamaban a voces y señas de los pañuelos a los ingleses para que vinieran a tierra; de lo que irritados los enemigos quisieron, doblando la viveza del fuego, infundir temor de él; [lo] que no habían logrado, ni lograron, pues aunque sus balas venían en tal número que del polvo que levantaban en la playa no se distinguía nuestra gente; se mantuvo con tal constancia y serenidad de ánimo, que obligó a Comandante a empeñar todo su respeto para hacerla retirar del consabido peligro en que estaba..." ${ }^{47}$.

Descorazonadas las tripulaciones de las fragatas, después de haber realizado unos ochocientos disparos de artillería en las veinticuatro horas de refriega, al medio día abandonaron la ensenada de Los Cristianos, después de haber producido una sola baja entre los defensores: un herido por «una lasca que hizo saltar de un risco una bala de cañón».

Cuatro son las notas destacables de este episodio. En primer lugar el comportamiento de las milicias, tanto que Mayoni suplica al marqués de la Ensenada que

"reflexione las circunstancias de ser toda la defensa, hecha por una milicia sin más conocimiento de la guerra que aquel que los induce su amor al Rey y a la Patria, y por lo que hallándose S. M. tan bien servido, los considero acreedores a sus piadosos efectos" ${ }^{48}$

En segundo, proponer el ascenso a teniente coronel al capitán comandante del Regimiento de Abona. En efecto, don Juan Rodríguez Feo, "que siendo hombre de más de 70 años de edad, se halló incansable en la fatiga». Oficial "que aseguro a V. E. operó tan bien como pudiera el más práctico militar ${ }^{49}$.

Tercera. La marquesa de Adeje tuvo una participación definitiva, porque sin la ayuda de su artillería, calidad de sus armas y abastecimiento, los acontecimientos hubieron transcurrido en otra forma. Estima Mayoni que de alguna manera el Rey le muestre su agrado.

4) Es curiosa la anécdota sucedida a Rodríguez Feo. Cuando trataba de evitar los peligros a los que bailaban en la playa, agachose para que pasara por arriba una descarga, pero explotaron sendas balas a ambos lados, que «lo dejaron enterrado en ella y tenido por muerto...; pero fue su fortuna que no recibiera daño alguno, libertándole para que alcanzase felizmente la función'. Relación cit.

48 Mayoni a Ensenada. SCT, 24,1.746. Leg. cit

49 LOC. cit. 
Finalmente, subrayar el carácter aún mesiánico de las Guerras de religión, como supervivencia. Según la Relación el hecho de sufrir una sola baja y leve entre los defensores, no pudo obedecer sino al favor divino. La prueba más palpable nos la ofrece el profesor Rumeu de Armas al confirmar con documentación parroquial que se tuvo por hecho portentoso y milagroso de la patrona de Adeje, la Virgen de la Encarnación ${ }^{50}$.

Felipe V, cercana ya su muerte, concede el ascenso a Rodríguez Feo, ordena acuñar medallas conmemorativas como obsequio a los valerosos defensores y encomienda al marqués de la Ensenada que haga llegar a la condesa marquesa una misiva con su agradecimiento ${ }^{51}$.

\section{Precauciones para los Azogues}

Con el triunfo de los Cristianos no acababan las preocupaciones del comandante general. Hay que ponderar como deja en un discreto silencio el éxito del sistema defensivo por él instaurado en el archipiélago contra la plaga de corsarios. Pleno éxito que explica cómo hasta la paz de Aquisgrán, en 1748 las islas disfrutaran de una absoluta tranquilidad por lo que al tráfico interinsular se refiere.

La preocupación se centra en dos extremos. Ignorancia sobre el rumbo que tomaron las dcs fragatas y su posible conjunción con el navio que operaba en estas latitudes y el temor por la flota de Azogues. Si ambas formaciones toparon y se perdiese algún cargamento de mercurio de Almadén, significaría una catástrofe, pues este era indispensable para obtener la plata mediante un proceso de amalgamiento.

Para evitarlo despachó con celeridad y absoluto sigilo una tartana muy marinera dirigida al intendente de Marina en Cádiz, Alejandro Rubalcaba. Y por si hubiera ya zarpado envió un barco ligero para que se situara entre Lanzarote y la Costa de Berbería, o sea "sobre el propio derrotero que en tiempos de guerra suelen traer los navíos que van a la América»,

5o Rumeu, A., 1991, tm. III, 270.

51 Ensenada a Mayoni. Minuta. s.f.; impreso con el ascenso a teniente coronel de Rodríguez Feo y carta a la marquesa. Como reflejo de una época es curioso el texto de la carta de la marquesa Doña Florencia Pizarro a Ensenada. Adeje, 25.4.745: «Muy favorecida me dejó la carta de V. E., especialmente en el gesto que muestra por el buen subceso que quiso Dios darme en la dirección y promtitud que serví de viveres y municiones desde este Castillo y Casa...; conozco el acrescentamiento de mi Casa siempre pronta al servicio de ambas Majestades, con el favor que S. M.... me ha hecho en dignarse llevar con aceptación este socorreo y quiera que $V$. E., en otros favores de mi Casa se halla obligada, diese a entender a S. M. el deseo que tengo de ampliar mi inutilidad en su RI. servicio". AGS, Guerra Moderna. Leg. 1309. 
al tiempo que prevenía al comandante de la escuadra «que huyan de esta Isla [Tenerife] y de la Gomera y la Palma, si no quieren ver a los enemigos ${ }^{52}$.

Terminada la Guerra de la Oreja y de la Sucesión de Austria la política de neutralidad fernandina conllevó un largo período de paz para las Islas Canarias, que fue alterado con la tardía intervención de Carlos III en la Guerra de los Siete Años, una vez firmado el denominado Tercer Pacto de Familia ${ }^{53}$.

\section{CONCLUSIONES}

El tema que hemos venido analizando es consecuencia de otro de mucha mayor enjundia en razón de la situación geográfica de las Islas en el cruce de las rutas atlánticas tricontinentales. Situación que las implicaron indefectiblemente en todos los conflictos navales de la modernidad. Además de escenario de ataques navales, hubieron de padecer enfermedad no menos peligrosa como el corso marítimo. Fenómeno éste que ha sido objeto en toda su complejidad por el profesor Rumeu de Armas en su magistral, dilatada y conocida obra ${ }^{54}$. Su valioso contenido me ha llevado a insinuar que semejante hecho histórico sea más un fenómeno «estructural» que un mero hecho de «larga duración» ${ }^{55}$.

Como es lógico en los cuatro decenios desde la aparición de esta obra han aparecido algunas nuevas fuentes, no muchas, que permitan establecer matizaciones, o incluso aportar algún episodio nuevo. Lo que me ha llevado a reflexionar, como decíamos al principio, sobre la trascendencia de tan complejo problema; reflexiones de las que pueden derivarse algunas nuevas conclusiones ${ }^{56}$. Esto me ha animado a presentar este fragmento de estudio divisible en dos partes de muy diferente entidad.

Mientras la Guerra de España contra la Liga de Hannover no supuso mayores estragos para las Canarias en razón de la práctica del comercio directo entre las islas e Inglaterra, la de la Oreja se caracterizó por su gran virulencia con ataques navales, corso, desembarcos, hostilidades y constantes alarmas.

52 Mayoni a Ensenada. SCT, 28.2.746. Leg. cit.

53 Palacio Atafio, V. 1945.

54 Rumeu de Armas, A., 1947-1950. Tres tomos en cinco volúmenes.

55 Béthencourt Massieu, A., 1992 b.

50 Béthencourt Massieu, A., 1994. 
Vimos y comentamos cómo durante aquélla, Santa Cruz de Tenerife jugó un papel privilegiado en el eje Cádiz-Tenerife-La Habana, abandonándose incluso el retorno por las Azores.

Por lo que toca a la segunda, destaca en primer lugar que la Guerra no les afectó linealmente, sino que nos permite introducir una periodización: 1. 1739-1743 de inusitada virulencia, consecuencia de la postura de armadores y comerciantes que esperaban obtener grandes beneficios del pillaje al poner fin al sistema pacifista imperante ${ }^{57} ; 2.1743-45$ de relativa tranquilidad, en busca del restablecimiento del «tráfico directo» más beneficioso que el obtenido por los corsistas, gracias al contrabando; 3. 1745 , ante las cortapisas españolas a este tipo de tráfico, de nuevo las islas se ven sometidas a la crueldad de la Guerra, pero don Luis Mayoni encuentra el antídoto adecuado que las inmuniza y 4. 1746-48 de calma absoluta, consecuencia de la eficacia del cierre de los puertos ante la presencia enemiga.

Conviene destacar por lo que toca a los incidentes relatados, a los que no sería dificil traer muchos ejemplos, el papel clave que juegan las milicias provinciales en el rechazo de los atacantes.

Este enfrentamiento secular entre canarios e ingleses, católicos y protestantes, originó un comportamiento colectivo por parte de los agredidos. De un lado reafirmar el españolismo de los isleños y su fidelidad a los monarcas reinantes. De otro, la pervivencia del mesianismo y el carácter todavía religioso de la guerra aun en el siglo XVIII, a pesar de estar esta centuria caracterizada por la tolerancia. De aquí el diferente comportamiento frente a los corsarios británicos, y la actitud a veces simpatizante con las de los insurgentes durante la Guerra de Independencia hispanoamericana. Hecho este explicable a causa del contacto permanente de las Islas con el Nuevo Mundo, hogar de millares de emigrantes ${ }^{58}$.

Finalmente, nunca insistiremos bastante, en el papel logístico que juegan las bases de apoyo: Funchal para los ingleses a lo largo de toda la Centuria ${ }^{59}$ y Santa Cruz de Tenerife para los franceses durante los conflictos de la Revolución y el Imperio.

\section{BIBLIOGRAFIA}

Abreu du Sousa, Joâo José, O movimiento do porto de Funchal e a cojuntura da Madeira de 1729 a 1810 . Alguns aspectos. Funchal 1989.

57 Béthencourt Massieu, A., 1965.

58 Podriamos traer a cuenta bastantes autores, pero como botones de muestra basten, PAZ SáNCHEZ, 1982 y 1990 y MaCías HeRNÁNDEZ, 1992.

59 Béthencourt Massieu, A., 1965 y Abreu de Sousa, J. J., 1989. 
Béthencourt Massieu, A. y Rodriguez Galindo, A., Ataques ingieses contra Fuerteventura. 1740. Valladolid 1965; y Puerto Cabras 1992 a.

Béthencourt Massieu, Antonio, «Los ataques a Fuerteventura en el contexto de la guerra de corso. Reflexiones", en Ataques ingleses a Fuerteventura. 1740. Puerto Cabras $1992 \mathrm{~b}$

- "Canarias y el Atlántico, historia de una estructura», en La Provincia (LPGC), 6-8-1992 C; El Día (SCT) 11-10-1992.c.

- Patiño en la politica internacional de Felipe $V$. Valladolid 1954.

- "Reflexiones sobre las repercusiones del corso marítimo en las Islas Canarias", en Coloquio As sociedades insulares no contexto das interinfluências culturais do seculo XVIII. Funchal 1993. (En prensa) 1994, págs. 51-92.

Cioranescu, Alejandro, "Piratas y corsarios en aguas de Canarias (siglo XVIII)», en Historia General de las Islas Canarias, de Millares Torres. Las Palmas de Gran Canaria 1977; tm. IV 111-123.

DaRIAS Y PADRón, Dacio V., Los Condes de La Gomera. Santa Cruz de Tenerife 1936.

Macias Hernández, Antonio M., Las migraciones canarias, 1500-1980. Columbres 1992

Palacio Atard, Vicente, El Tercer Pacto de Familia. Madrid 1945

PAZ SANChez, M., "El corso argentino en Canarias durante la emancipación americana», en $X$ Jornadas de Estudios Canarias-América. Los canarios en el estuario del puerto de la Plata. Santa Cruz de Tenerife 1990.

- "Corsarios insurgentes en aguas de Canarias (1816-1828)", en VCHCA (1982). Las Palmas de Gran Canaria 1985.

Rumeu de Armas, Antonio, Canarias y el Atiántico. Piraterias y ataques navales. Canarias 1991

-- Piraterías y ataques navales contra las Islas Canarias. Madrid 1947-1950.

Santiago Rodriguez, Miguel, "Windon en La Gomera, Palma y Gran Canaria, de mayo a junio de 1743", en Revista de Historia Canaria, núm. 63-64. La Laguna 1943.

- "Woodes Rogers en Canarias». Revista de Historia (La Laguna), 66(1944), $156-172$.

VAUCHER, Paul, Robert Walpole et la politique de Fleury, 1731-1742. París 1924.

Viefa y Clavijo, José, Noticias de la Historia General de las Islas Canarias. Octava edición. Santa Cruz de Tenerife 1982 